\title{
IV. Ein Fall von muqueusen Plaques an den Genitalien eines Kindes und Beurtheilung des Modus der Syphilis-Uebertragung in forensischer Beziehung.
}

Von

Dr. J. Edm. Güntz in Dresden.

Ein Mädchen von 9 Jahren wurde in der Poliklinik vorgestellt, bei welchein an den Genitalien Syphiliserscheinungen, Plaques muqueuses vorhanden waren. Es wurde von den Augehörigen die Frage gestellt, ob mit Bestinnntheit ein Missbrauch des Kindes anzunehmen sei. Das Mädchen hatte geleugnet. Die Frage konnte nicht mit Bestimmtheit beantwortet werden. Aehnliche Fälle haben in forensischer Bezieluungr grosse Bedeutung, in sofern es den Arzt, Richter und Geschworenen bei dem derzeitigen Mangel weiterer Syphiliserscheinungen an anderen Körperstellen, bei einer wie hier klar ausgesprochenen syphilitischen Genitalaflection verlockend erscheinen kaun, (irrthümlich) eine syphilitische Uebertragung an den Genitalien für bewiesen zu erachten. Namentlich für Geschworene kann es sehr plausibel scheinen, bei deutlich ausgesprochener syphilitischer Geschlechtserkrankung einen Missbrauch vorauszusetzen, da es im grösseren Publikum nicht behannt ist, dass die Syphilis nicht blos an den Genitalien, sondern auch an anderen Stellen des Körpers Eingang finden kann. Es ist ebensowenig bekannt, dass, wenn die Syphilis irgendwo am Körper, entfernt von den Genitalien übertragen wurde, sich Plaques muqueuses nachträglich an den Genitalien, wie muthmasslich in den vorliegenden Falle bilden können, welche unter Umständen genau dasselbe Aussehen haben, wie solche Affectionen der Genitalien, welche durch directe geschlechtliche Berührung entstehen. Die Eingangsstellen des syphilitischen Giftes in den Körper sind nicht zu allen Zeiten beobachthar, weil sie oft unscheinbar, unverdächtig und ganz uncharakteristisch sind. Bei dem Kind bestand eine Narbe an der Lippe, welche ebensowohl als inuthmassliche Eingangsstelle der Syphilis angesprochen, als auch möglicher Weise auf andere Art entstanden angeselen werden konnte. Aus begreiflichen Gründen finden die meisten syphilitischen Ansteckungen an den Genitalien statt, - aber der Einzelfall ist imner besonders für sich zu beurtheilen. Bei dem Mangel solcher Syphiliserscheinungen, wie Drüsenanschwellungen in der Nähe des Ansteckungsherdes, hier bei dem Mangel der Leistendrüsenanschwellung in der Nähe des Genitalgeschwürs, hatte der Verfasser trotz der vorhandenen Syphilis den Angehörigen des Kindes gegenüber die Verpflichtung, dem Standpunkt der Wissenschaft entsprechend, ein auf die bestimmt gestellte Frage bejahendes Urtheil nicht abzugeben. 